\title{
Terre de pêcheries
}

Marie-Yvane Daire

\section{OpenEdition}

Journals

Édition électronique

URL : http://journals.openedition.org/rao/2241

DOI : 10.4000/rao.2241

ISBN : 978-2-7535-3432-2

ISSN : 1775-3732

Éditeur

Presses universitaires de Rennes

Édition imprimée

Date de publication : 25 décembre 2013

Pagination : 323

ISBN : 978-2-7535-3430-8

ISSN : 0767-709X

\section{Référence électronique}

Marie-Yvane Daire, "Terre de pêcheries », Revue archéologique de l'Ouest [En ligne], 30 | 2013, mis en ligne le 25 décembre 2013, consulté le 04 décembre 2020. URL : http://journals.openedition.org/rao/ 2241 ; DOI : https://doi.org/10.4000/rao.2241

Ce document a été généré automatiquement le 4 décembre 2020.

Tous droits réservés 


\title{
Terre de pêcheries
}

\author{
Marie-Yvane Daire
}

\section{RÉFÉRENCE}

Billard C. (dir.), 2012 - Terre de pêcheries. 4000 ans d'archéologie et d'histoire sur le littoral de la Manche, Bayeux, éd. OREP/Centre régional de Culture ethnologique et technique de Basse-Normandie (CRéCET), coll. « Les Carnets d'ici - Patrimoine ethnologique et technique de Normandie », 128 p. (ISBN : 978-2-8151-0129-5)

1 Cet ouvrage coordonné par Cyrille Billard constitue l'élégante publication qui accompagne l'exposition «Terre de pêcheries. 4000 ans d'archéologie et d'histoire sur le littoral de la Manche ». Plus qu'un simple catalogue, cet ouvrage illustré avec finesse est une véritable invitation à (re-)découvrir un patrimoine ancestral, encore trop souvent méconnu, celui des pièges et barrages de pêcheries des côtes de la Manche, principalement celles du département du même nom. Conciliant démarche historique et archéologique, témoignages d'exploitants et approches interdisciplinaires, l'ouvrage démontre tout le caractère emblématique de ces éléments du patrimoine culturel littoral.

2 La remarquable qualité du contenu et de la forme donne à regretter que l'ouvrage ne fasse «que» 128 pages... Le lecteur, ainsi «ferré », aurait volontiers poursuivi la ballade sur quelques dizaines (centaines) de pages supplémentaires.

3 Après une introduction comportant une définition du principe d'une pêcherie, puis un panorama technique des pêcheries actuelles dans le monde, le volume est structuré en deux parties. La première section, dédiée à l'« Archéologie et histoire des pêcheries » retrace rapidement l'histoire de la recherche archéologique sur les pêcheries, en Europe et dans l'Ouest de la France, et plus précisément en Normandie; le lecteur y découvre l'envergure des pêcheries préhistoriques, les rythmes de leur construction et de leur exploitation (Champeaux, Saint-Jean-le-Thomas), mais aussi l'histoire des installations médiévales (Champeaux à nouveau, Saint-Lô-d'Ourville, Saint-Pair-surMer), ou encore les débuts de la législation et leurs effets sur les pêcheries fixes 
postmédiévales ( $\mathrm{XVI}^{\mathrm{e}}-\mathrm{XVIII}{ }^{\mathrm{e}}$ siècle). En guise de transition, un panorama dédié à l'époque contemporaine montre que le nombre des pêcheries n'a pas diminué...

4 La seconde partie du volume apporte l'éclairage des témoignages de l'époque contemporaine, à travers les noms des pêcheries, l'observation des techniques traditionnelles de pêche dans le golfe normano-breton, des données qualitatives et quantitatives sur les poissons piégés, des portraits de pêcheurs et de pêcheries... dont l'avenir est à la fois pluriel et précaire.

5 Les auteurs terminent ainsi le résumé de la quatrième de couverture : "Cette plongée dans une aventure humaine et technique de plus de quatre mille ans est une invitation à fouler les imposantes grèves des côtes de la Manche et à y porter un regard nouveau ». Tout est là !

\section{AUTEURS}

\section{MARIE-YVANE DAIRE}

CNRS, UMR 6566 « CReAAH », Rennes 